\title{
2010 Karakocan-Elazig earthquake and masonry structures
}

\author{
N. Cetinkaya \\ Department of Civil Engineering, Inonu University, Malatya, Turkey \\ Received: 7 September 2010 - Revised: 10 November 2010 - Accepted: 10 November 2010 - Published: 4 January 2011
}

\begin{abstract}
Karakocan-Elazig-Turkey earthquake with $M=6.0$ occurred on 8 March 2010 at 04:32 a.m. (local time) in eastern Turkey and caused the loss of life and heavy damages, as well. The majority of the damaged structures were seismically deficient, unreinforced masonry buildings. In this paper, a site survey of the damaged buildings is presented and the reasons behind the damages are discussed.
\end{abstract}

\section{Introduction}

Most of the masonry structures are seismically deficient in Turkey. A huge population live in these structures which constitute an important percentage of the building stock.

8 March 2010 Karakocan-Elazig earthquake of magnitude 6.0 occurred at a region where masonry and adobe construction is very common. Karakocan-Elazig is located in a high seismicity region on Eastern Anatolian Fault System (EAFS) (Fig. 1). Due to the earthquake, 42 people were killed and 14113 buildings were damaged (Elazig Governor, 2010).

This earthquake caused extensive damages to the unreinforced masonry buildings. Many of the damaged buildings were unreinforced stone masonry or adobe with low construction quality. In this paper, the results of the site survey are presented and the lessons learned from the earthquake are discussed.

\section{Seismological and geotechnical issues}

8 March 2010 Karakocan-Elazig earthquake occurred on EAFS which is one of the most active fault systems of the world. EAFS is composed of six fault segments, which are Karliova-Bingol, Palu-Hazar, Hazar-Sincik, CelikhanGolbasi, Golbasi-Turkoglu and Turkoglu-Hatay fault segments (Fig. 2). This earthquake was related to the faults at the eastern end of Palu segment.

Most of the heavily damaged villages have been located on the hills with high slope. Therefore, the topographic amplification was effective on the severity of the damages similar to some of the previously reported cases (Capua et al., 2006; Jibson, 1987; Kaplan et al., 2008). Some researchers reported that ground accelerations could increase up to 2.5 times on the hills (Jibson, 1987).

Peak acceleration values recorded by five stations for the earthquake are given in Table 1. The nearest station to the epicentre was Palu station having an epicentral distance of $12 \mathrm{~km}$. The corrected components of the record are shown in Fig. 3. The epicentral distances of the buildings with heavy damages were ranging from $4.8 \mathrm{~km}$ to $10.0 \mathrm{~km}$.

Maximum soil amplification value obtained from the Palu strong motion station is about 5 and it is seen from dominant frequencies that soils are generally from the stiff soil classification (ED Earthquake Department at Disaster and Emergency Management Presidency of Turkey ${ }^{1}$ ).

The duration of the earthquake is another important part affecting the level of the structural damages during the strong motion. According to the Palu station records, the earthquake lasted for $13.77 \mathrm{~s}$ in EW and $15.52 \mathrm{~s}$ in the NS direction.

For the calculation of the forces imposed by the earthquake, the spectral accelerations of the records were calculated (Fig. 4). Damping ratios between 2\% and 10\% are proposed for masonry structures (Sucuoglu and Erberik, 1997; Freeman, 2004; Tomazevic et al., 2006). Damping in masonry walls is achieved by the friction forces in the cracks (Gulkan and Langenbach, 2004). However, nonlinear damping characteristics of the unreinforced masonry structures are not well known at the moment.

\footnotetext{
${ }^{1}$ www.deprem.gov.tr, last access: 6 August 2010
}

Published by Copernicus Publications on behalf of the European Geosciences Union. 


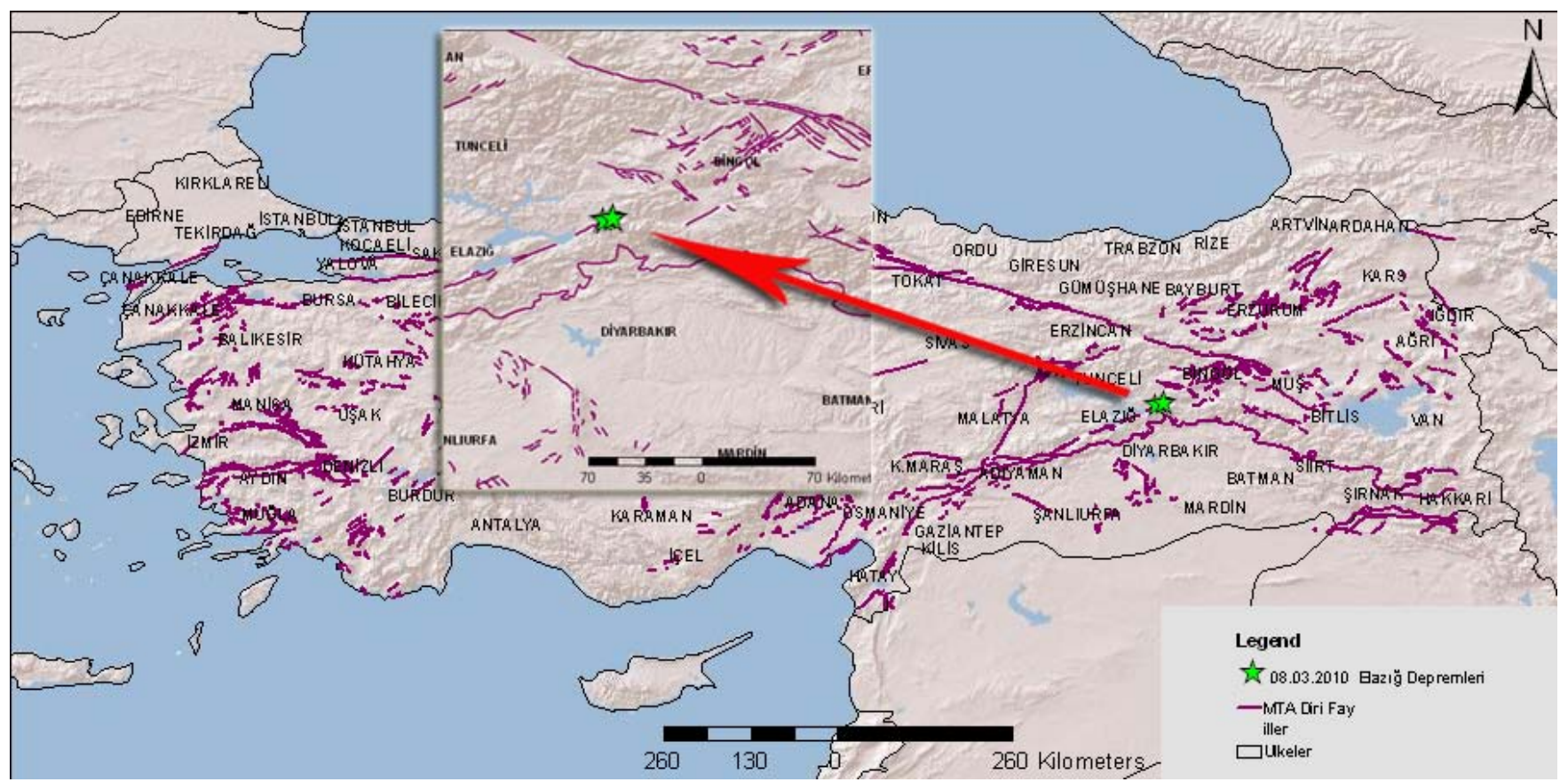

Fig. 1. Karakocan-Elazig earthquake (ED, 2010).

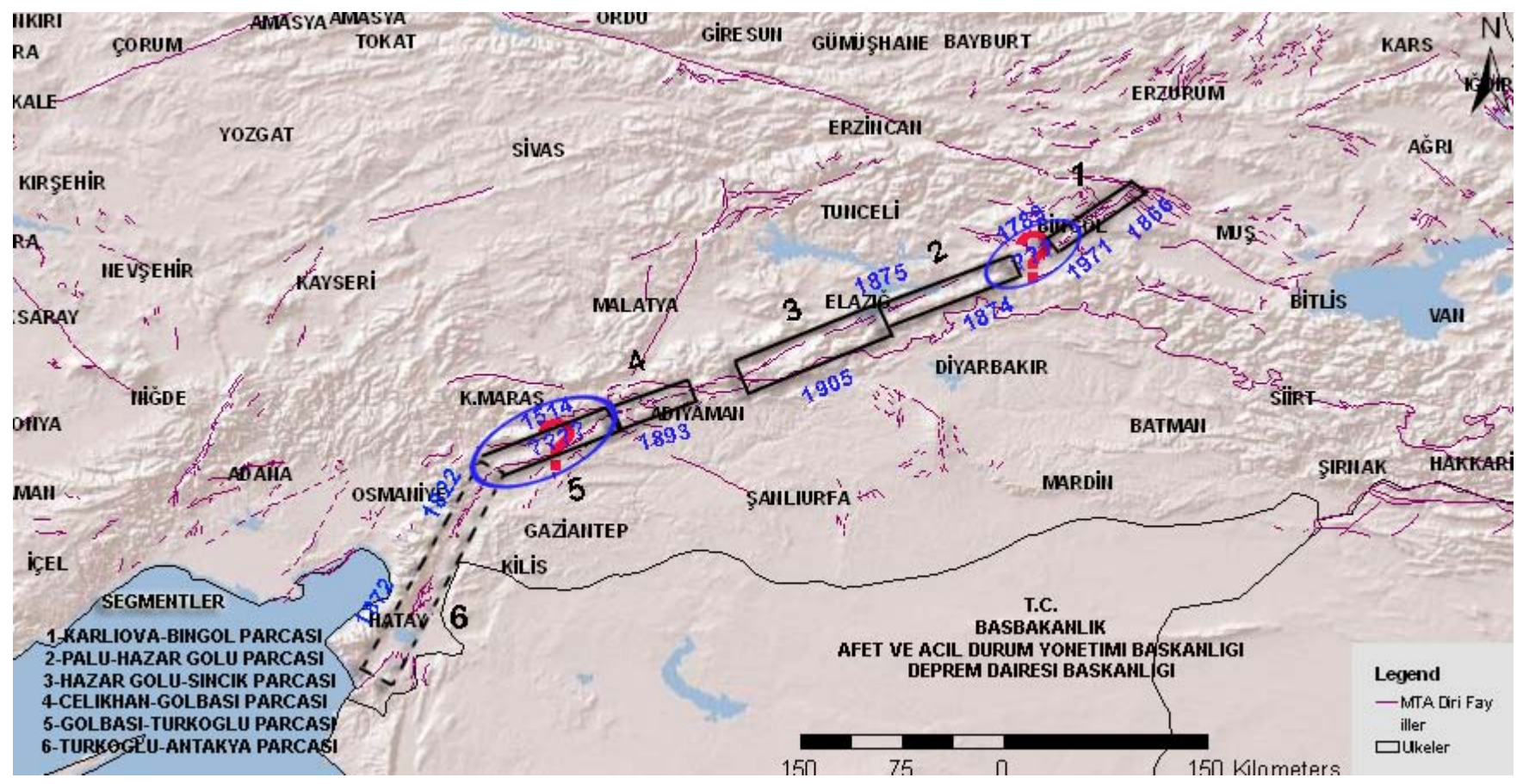

Fig. 2. EAFS and Karakocan-Elazig earthquake (ED, 2010). 


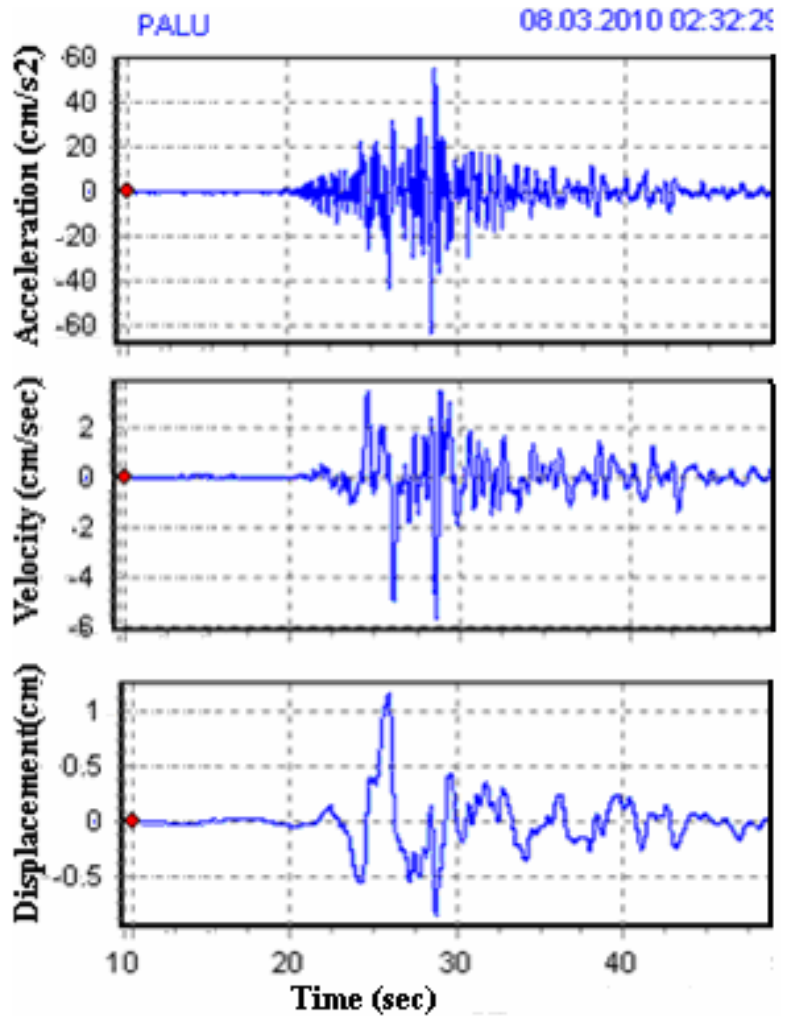

Fig. 3. Palu station acceleration records (ED, 2010).

\section{Structural damages at masonry buildings due to the earthquake}

The masonry buildings in the region affected by the earthquake were constructed using mud bricks, stones collected from the river beds, soft natural stone blocks and lime hollow/solid blocks. Most of the buildings were one-storey with a very heavy roof over a wooden skeleton (Fig. 5). This type of heavy roofing significantly increases the seismic demands. These buildings were not earthquake resistant according to previous or existing Turkish seismic codes (MPW, 1975, 1998, 2007).

Although the magnitude and spectral acceleration values of the Earthquake were not so high, many masonry buildings were heavily damaged due to the above-mentioned construction practice. The disaster area was surveyed and detailed studies were carried out on the damaged buildings to understand the reasons of the poor performance of the masonry buildings. The main reasons are discussed in detail with the examples of damaged buildings.

One of the most common reasons was the use of wrong material. Rubble stone and shaped soft stone blocks were the wall materials commonly used in the damaged buildings. Soft stone blocks have low strength and ductility values. The rubble stone blocks selected from the river beds used
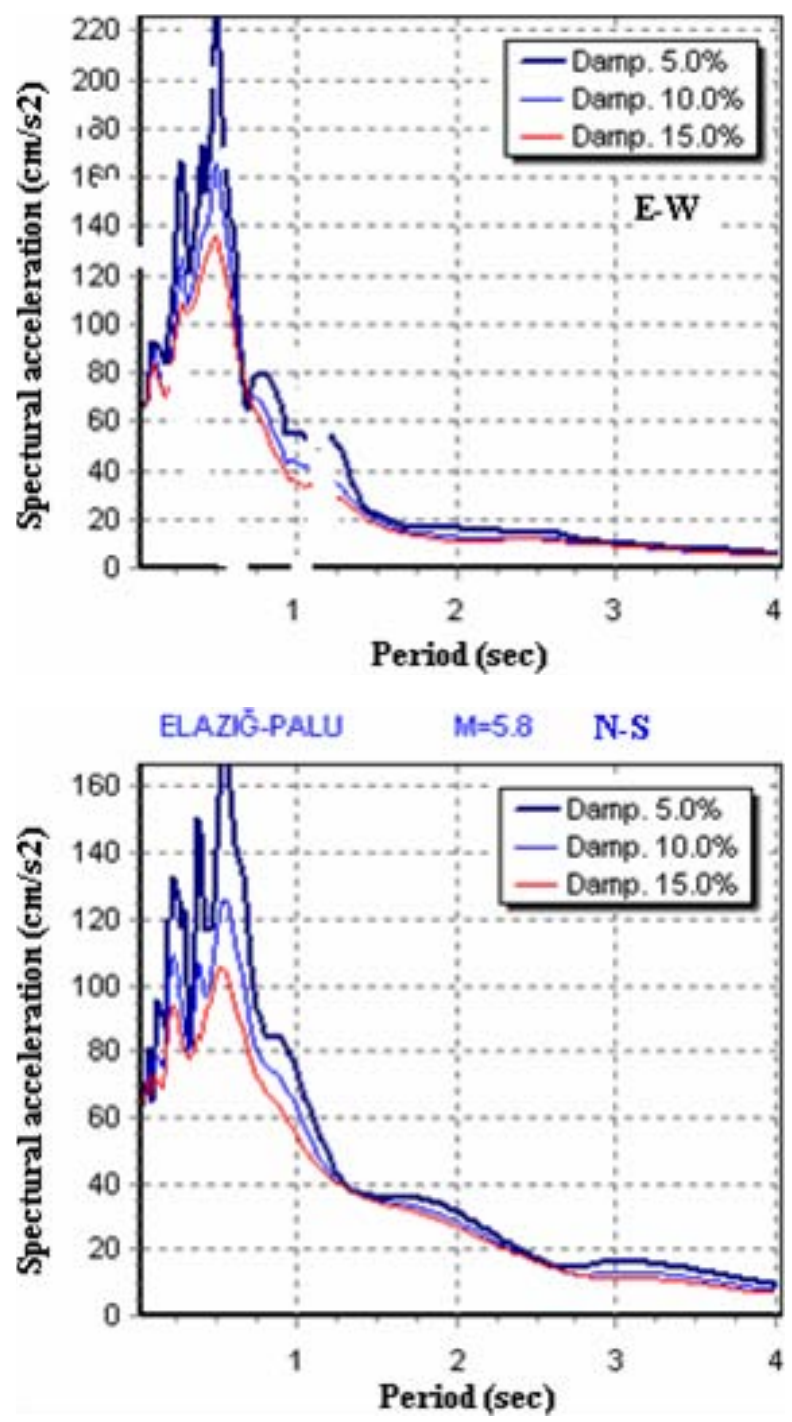

Fig. 4. Spectral accelerations of the earthquake (ED, 2010).

Table 1. Peak acceleration values (ED, 2010).

\begin{tabular}{|c|c|c|c|c|}
\hline \multirow[t]{2}{*}{$\begin{array}{l}\text { Recording } \\
\text { Station }\end{array}$} & \multirow[t]{2}{*}{$\begin{array}{l}\text { Epicentral } \\
\text { Distance } \\
(\mathrm{km})\end{array}$} & \multicolumn{3}{|c|}{$\begin{array}{l}\text { Peak Ground } \\
\text { Acceleration } \\
\left(\mathrm{cm} \mathrm{s}^{-2}\right)\end{array}$} \\
\hline & & $\begin{array}{c}\mathrm{N}-\mathrm{S} \\
\text { Compo. }\end{array}$ & $\begin{array}{c}\text { E-W } \\
\text { Compo. }\end{array}$ & $\begin{array}{l}\text { Vertical } \\
\text { Compo. }\end{array}$ \\
\hline Palu & 12 & 62.00 & 66.50 & 30.00 \\
\hline Bingöl & 43 & 55.31 & 34.26 & 25.50 \\
\hline Elazĭ̆ & 74 & 5.56 & 4.76 & 3.84 \\
\hline Solhan & 90 & 28.5 & 29.0 & 12.0 \\
\hline Diyarbakir & 95 & 3.44 & 5.10 & 3.59 \\
\hline
\end{tabular}




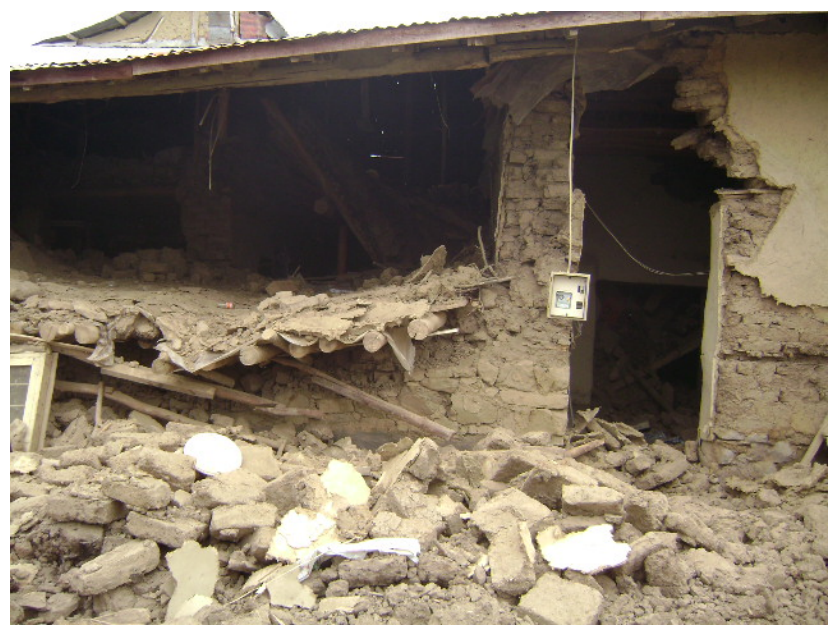

Fig. 5. Heavy roofing with wooden skeleton.

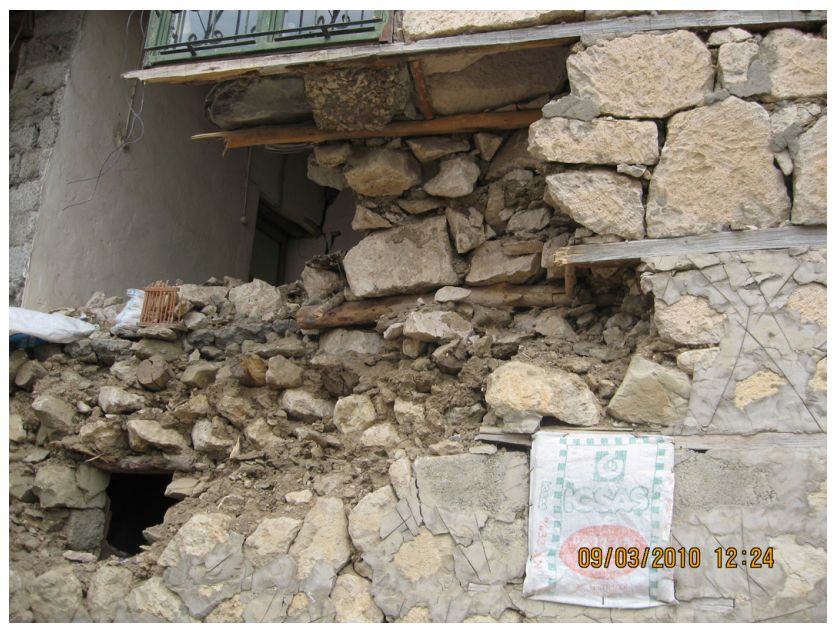

Fig. 6. No interlocking between wall leaves.

as wall material do not have a proper shape for the use in the masonry walls. They have smooth and oval surfaces with irregular sizes. It is not possible to construct an overlapping wall section using this kind of material without cutting them into proper sizes and shapes.

The stone masonry walls were constructed as inner and outer leaves with a total thickness of $50 \mathrm{~cm}$ in general. There was no interlocking element to connect the inner and outer leaves to each other. Because of this deficiency, the unsupported length of the outer leaf of the wall was doubled, but its effective thickness was decreased to half of the wall thickness. So, the out-of-plane failure risk was considerably increased. This type of damage is shown in Fig. 6.

Another common reason for the damages was the insufficient connection of the walls to each other. There was either no connection or the connection was not constructed properly to transfer the loads. This kind of damage is shown in Fig. 7. The construction of the exterior walls was

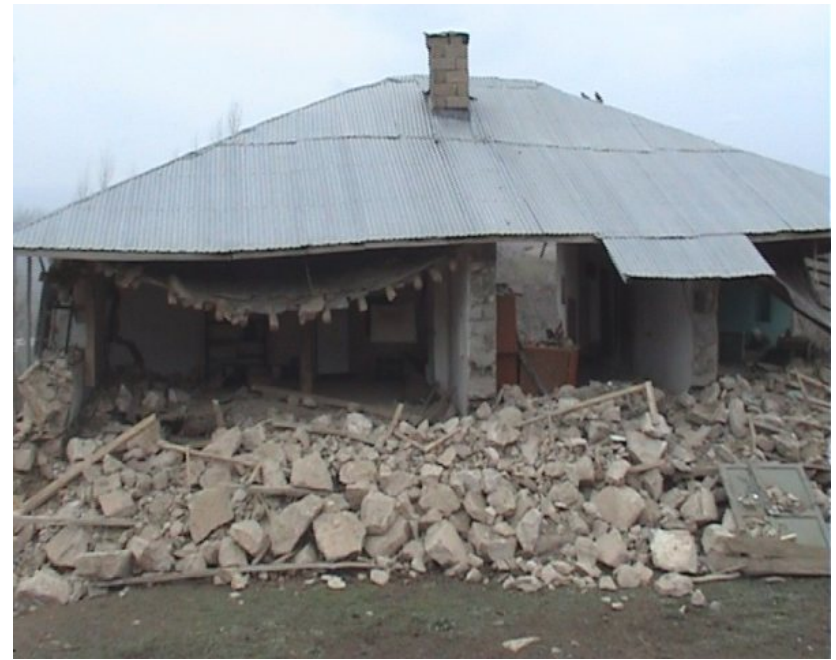

Fig. 7. No connection to partition walls.

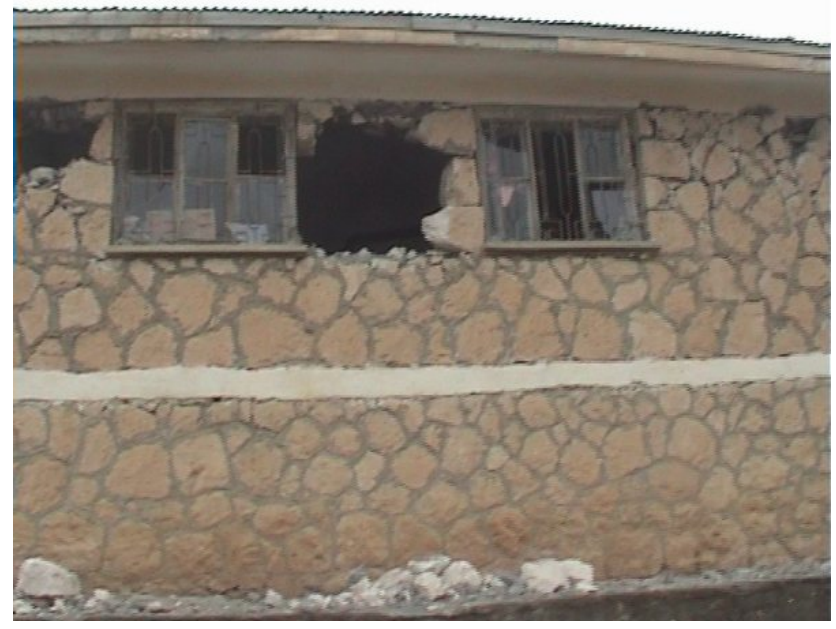

Fig. 8. Short distance between two openings

completed without any connection to partition walls. For this reason, the free span of the external wall was too much to resist against out-of-plane failure.

Wrong placement of the openings in the walls was among the most common reasons for the damage. Since the masonry walls are the only lateral load bearing structural elements of the masonry buildings, seismic design codes restrict the distance between the two openings and the distance between the opening and corner of the walls (MPW, 1975, 1998, 2007). The minimum distance between two openings should be $1 \mathrm{~m}$ and the minimum distance between an opening and a building corner should be $1.5 \mathrm{~m}$. The damage due to the insufficient distance between two windows is shown in Fig. 8. Irregular shape of the masonry units in Fig. 7 is also as important as the insufficient wall length. Besides, it should be noted that the damage level in that wall could be higher 


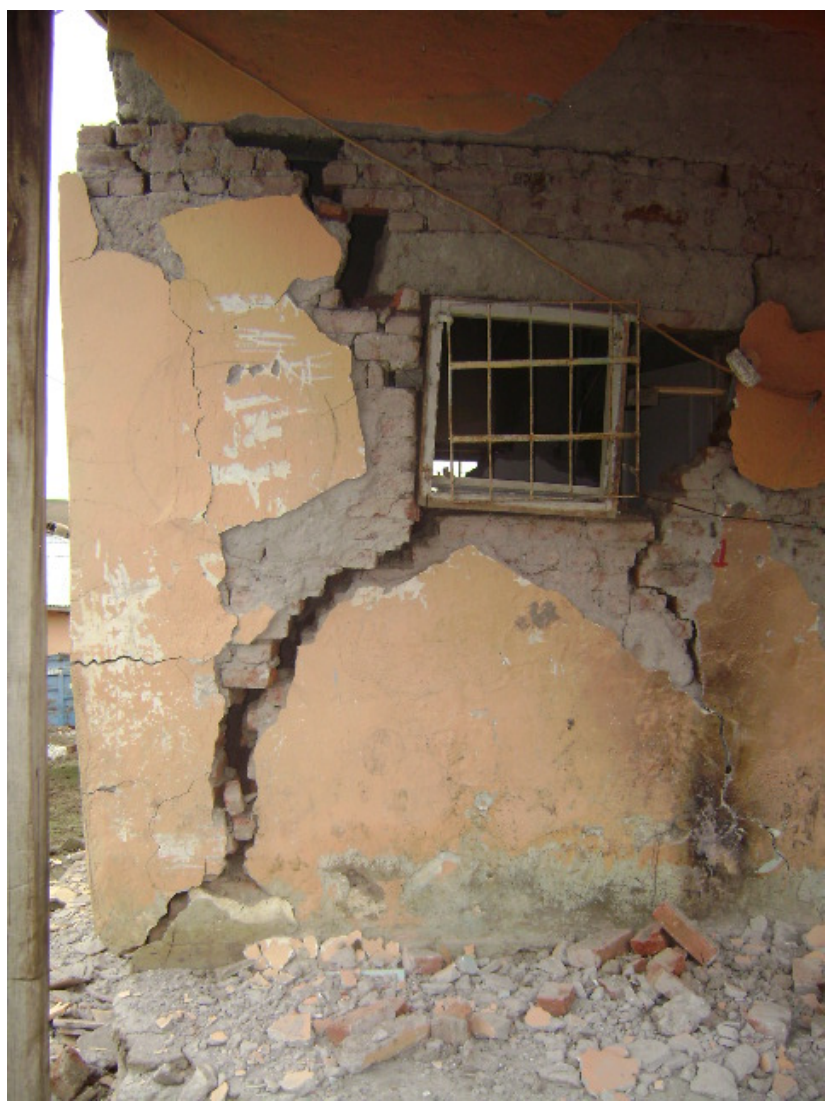

Fig. 9. Wall opening close to the building corner.

if the bonding beams at mid-height and at the top of the walls were not. The damage shown in Fig. 9 was due to the insufficient distance between the opening and the building corner.

The lack of bond beams on top of the walls and a heavy roof with insufficient in-plane stiffness, which does not provide a rigid diaphragm effect, are also important reasons for this type of damage (Fig. 10). Walls, bond beams and roof were not connected to each other to transfer the seismic loads. Therefore, the walls acted as free standing walls.

The buildings used as an animal shed had no partitioning wall. So, the long unsupported external walls collapsed outof-plane.

The poor quality of bonding mortar, as it is observed in most of the figures, is another important reason for the damages.

Topography of the region was also effective in the damages. Many of the damaged buildings were located on the hills with a high slope. According to Kramer (1996), topographical irregularities on ground surface may affect ground acceleration significantly. Because of the amplified ground accelerations, the number of the damaged buildings increased significantly. The damages on the buildings located on a hill are shown in Fig. 11. Due to the

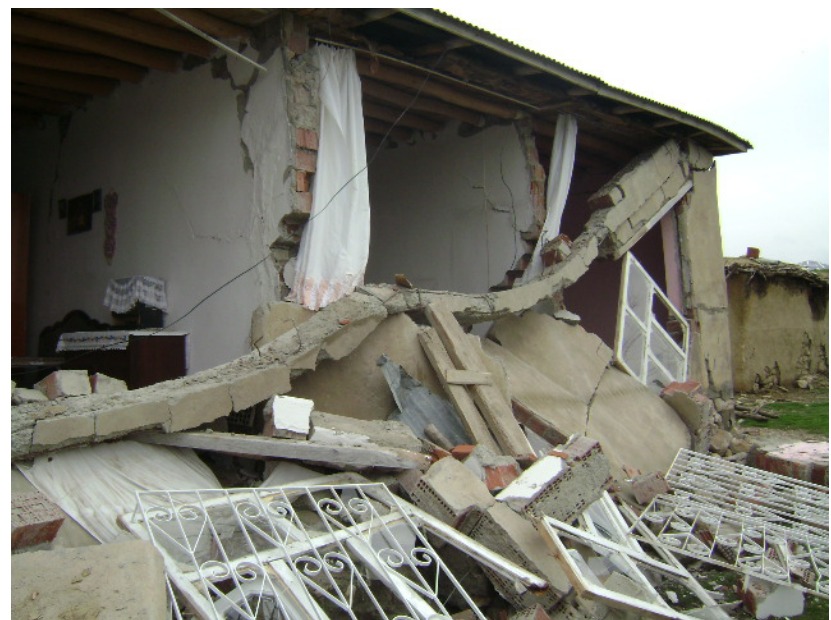

Fig. 10. Out-of-plane failure due to long span.

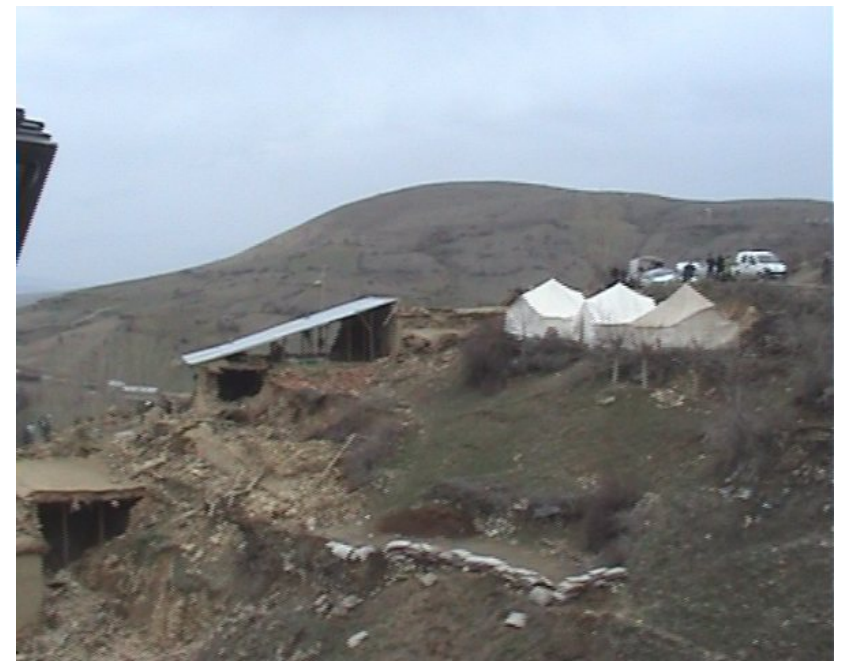

Fig. 11. Damaged buildings on a hill with high slope.

concentration of seismic energy and amplification of the ground acceleration at the top of the hill, the damage level of the building becomes heavier than those located on the foot of the hill.

\section{Conclusions}

The damages occurred mostly in the rural areas with onestorey unreinforced masonry structures. The most important defects of the damaged masonry structures were the lack of interlocking units between external and internal leaves of the wall sections and the lack of connection between crossing walls. Both of them caused an increase in the possibility of out-of-plane failure, as their formation increases net length of the walls or leaves. 
Lack of bond beams at the top of walls was another common reason for damages. A heavy roof was placed directly on the walls. This heavy roofing increased the seismic demands and caused the damages.

Improper placement of openings was also a common reason for damage. Cracks were concentrated around the openings.

Soil amplification due to slope hill effect and local soil conditions increased ground accelerations and the damages.

The masonry buildings, especially in rural areas of Turkey similar to the ones in the developing countries all over the world, are under high risk of significant damage in the future earthquakes. Therefore, it is very urgent to take necessary precautions to reduce the seismic damage risk in the masonry structures. Economical and applicable strengthening techniques for the existing masonry structures must be developed.

Acknowledgements. Autor thanks to the Inonu University for its support.

Edited by: M. E. Contadakis

Reviewed by: two anonymous referees

\section{References}

Capua, G. D., Curti, E., Lemme, A., Peppoloni, S., and Podestà, S.: Simplified parameters for the evaluation of site effects in the seismic risk analyses of monuments, First European Conference on Earthquake Engineering and Seismology, Geneva, Paper No. 656, 10 pp., 2006.

Gulkan, P. and Langenbach, R.: The earthquake resistance of traditional timber and masonry dwellings in Turkey, 13th World Conference on Earthquake Engineering, Vancouver, Canada, Paper No. 2297, 2004

Jibson, R.: Summary on research on the effects of topographic amplification of earthquake shaking on slope stability, USGS, California, Open File Report, No. 87-268, 166 pp., 1987.

Kramer, S. L.: Geotechnical Earthquake Engineering, Prentice Hall, New Jersey, 1996.

Ministry of PublicWorks and Settlement: Regulations for structures to be built in disaster areas, Ankara, 1975, 1998, 2007 (in Turkish).

Office of Elazig Governor: Karakocan Eartquake damage statistics, 2010 (in Turkish).

Sucuoglu, H. and Erberik, A.: Performance evaluation of a three storey unreinforced masonry building during the 1992 Erzincan earthquake, Earthq. Eng. Struct. D., 26, 319-336, 1997. 